\title{
Design and Development of Module Coding System Oriented on CNC Machine Tools
}

\author{
Zhongqi Sheng, Shujian Zhang and Junyou Song \\ School of Mechanical Engineering and Automation, Northeastern University, \\ Shenyang, Liaoning, 110819, P.R. China \\ zhqsheng@mail.neu.edu.cn, ${ }^{2}$ zhangshujianvip@163.com, ${ }^{3}$ songjunyou120@163.com
}

\begin{abstract}
Modular design is one of the modern design methods used for the development of CNC machine tools, which can shorten the product design and manufacturing cycle, and improve the product quality and reliability. Module coding is one of the important steps in carrying out the modular design. Aiming at the effective application and management of the module codes in the enterprise informatization, this paper studied and developed the module coding system oriented on CNC machine tools. First, this paper analyzed the purpose of the module coding and put forward the basic rules of the module coding. Then, considering the characteristics of the modular design for CNC machine tools, this paper determined the coding scheme fit to the requirements of the machine tools enterprise. Next, based on the popular B/S structure and J2EE platform, this paper completed the function design and software development of the module coding system. At last, the development environment and example interface were introduced. The application of this module coding system in one machine tools enterprise proved that it was powerful to promote the application of modular design and the realization of the enterprise informatization.
\end{abstract}

Keywords: Coding system, Modular design, CNC machine tools, Informatization

\section{Introduction}

CNC machine tool is one of the key equipment in manufacturing industry and a symbol of advanced manufacturing technology. For the machine tool enterprises, they must improve the quality and performance of their products through advanced design methods so as to cope with rigorous challenges. Modular design is one of the modern design methods used for the development of CNC machine tools, which can shorten the product design and manufacturing cycle, and improve the product quality and reliability $[1,2,3]$. The design and production management of the products developed by the modular design method are mainly conducted through manipulating the modules. For the convenience of module management, it is necessary to accomplish the proper classification and effective coding of the modules used in the module design process [4]. Module coding is an important step in carrying out the modular design method. For modular design, the reasonable and effective module coding, which is beneficial to module division, module configuration, module management and other related work, is the premise and foundation of modular design and manufacturing [5]. In addition, to make the most of the potential of the modules as well as to meet the user requirements on various $\mathrm{CNC}$ machine tools rapidly, it is necessary to develop an appropriate 
software system for the module coding based on information and communication technology (ICT) [6]. Aiming at the effective coding and management of the modules, this paper studied and developed the module coding system oriented on CNC machine tools.

\section{The Function and Rules of Module Coding}

In order to describe the attributes and features of the modules properly and clearly, and to avoid the lengthy and ambiguity written description, it is necessary to use the specified character set, which is called module code, to represent the complex information about the modules for the design and manufacturing processes of the products.

\subsection{The function of module coding}

The function of module coding is to organize the module subordination relationship, the product specifications, the properties parameters and other related information according to the needs of the information management system for the modular design and manufacturing processes. By the module coding system, the designers can give every function module complete definition and naming, and determine the content, scope, representation method etc. which are used for modular design and manufacturing of the products. In this paper, CNC machine tools are used as the application object of this module coding system.

Effective module coding can show the necessary information of the modules for modular design method according to given classification rule, indicate the position of the modules in the product structure, and establish the common recognition, unified language and logo in certain range of the product design and manufacturing processes.

\subsection{The rules of module coding}

Module coding is the naming of the modules used in the modular design process. Proper rules of the module coding can not only furthest eliminate the divergences caused by inconsistent description about the module name, classification and function, etc., but also reduce the mistakes such as one object having many names or one name for many objects. The formulation of the module coding should obey the following rules [7, 8].

(1) Uniqueness: Establish the one-to-one mapping relationship between the module code and the corresponding object. Both the module code which has many corresponding objects and the module codes which have the same corresponding object are meaningless codes.

(2) Rationality: The coding system must describe the module and the information of all parts included in the module accurately and scientifically. At the same time, it must follow the basic coding principle and the relevant classification standards for CNC machine tools. The coding system should be regular and be understood, grasped, memorized and recognized easily.

(3) Practicability and intuition: The coding system should reflect the characteristics of the coding object such as the structure, function and production as far as possible. And it should make the code be practical, intuitive, and convenient for module division, module configuration, module management, module production and application in the development of new product and series products.

(4) Simplification and convenience: As far as possible completely describing main information of the coding object, the module coding should be simple and convenient to master. In order to save the storage space, easily remember and retrieve, and reduce the error 
rate, the module coding bits should be as short as possible, which can improve the computer processing speed, and help the designers improve the production and management.

(5) Inheritance: Considering the actual situation of the enterprises appropriately and meeting the needs of modular design, the module coding makes the change of original standards of the enterprises such as the product numbers and drawing numbers as little as possible.

(6) Extensibility: Both considering current scale and level of the production and the varieties of different product specifications and making a long-term planning, the module coding should be extensible so as to be beneficial to future product design and development trend.

(7) Adaptability: Module codes should be easy to modify so as to adapt to the characteristics or attributes of the coding objects and the possible changes of the correlations.

(8) Stability: Module coding should not be changed frequently. If the possibility of the changes is fully considered, it will keep the coding system as stable as possible.

\section{The Rules of Module Coding Oriented on CNC Machine Tools}

The general module coding proposed in this paper, which is suitable for the product family of CNC machine tools and the modules, is divided into three parts, named module master code, module interface code and module drawing code respectively.

\subsection{Module master code}

In modular design, the module master code is mainly used for the selection and management of the modules. Module master code is divided into two parts, named machine code and module code respectively. The coding rule proposed in this paper for module master code of $\mathrm{CNC}$ machine tools is shown in figure 1.

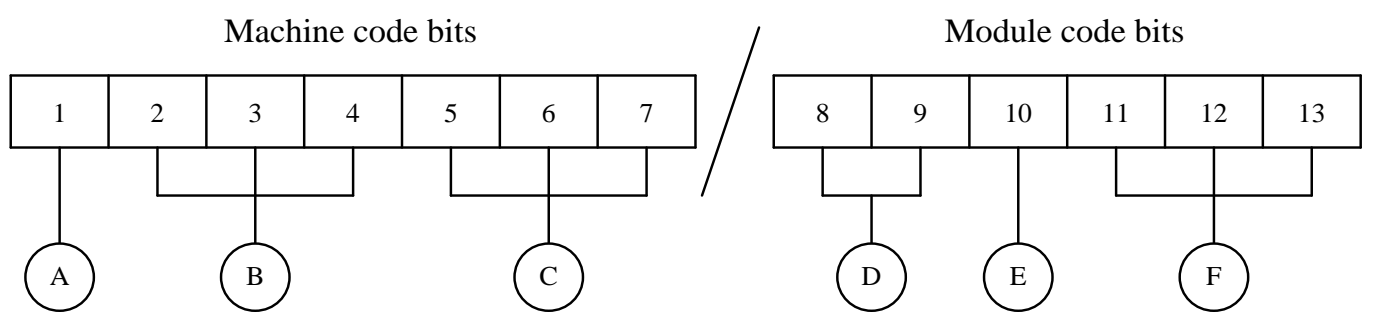

Figure 1. The coding rule of module master code for CNC machine tools

A: version number of the coding system using one code bit. It is applied to identify the version information and the application range of the coding rule, and additionally reserve the space for the improvement of coding system development.

B: category code for machine tools using three code bits. It is used to describe the categories of specific machine tool that belongs to the product family.

C: specification code for machine tools using three code bits. It is devoted to represent the specification and the type of $\mathrm{CNC}$ machine tools. A specification code corresponding to a type of $\mathrm{CNC}$ machine tools is mainly used to describe the main parameter of $\mathrm{CNC}$ machine tools. 
D: module classification code using two code bits. It is used to describe the module that the parts belong to.

E: part characteristic code using one code bit. It is used to indicate the basic type of the part included in the module. It can be indicated by the letters. For example, $\mathrm{H}$ represents the weld part, $\mathrm{L}$ represents the part, and $\mathrm{S}$ represents sub-unit (Note: Part refers to the minimum unit of the non-standard products designed by the enterprise. Sub-unit refers to the unit that can be divided into several parts according to the habits of the design and production in the enterprise).

F: part classification code using three code bits. Different classification codes for the parts correspond to different parts.

The coding rule of module master code proposed in this paper uses 13 code bits and includes 6 kinds of code, which is suitable for the module coding of CNC machine tools. Each code bit must have the corresponding letter or number while coding. The meaning of each code bit should be described in detail in the coding chart. When used in other ways, the numbers of the code bits can be appropriately extended.

The detailed coding rule for the machine code of $\mathrm{CNC}$ horizontal lathe adopting the above rules are shown in Table 1. Additionally several continuous code bits of the module master code can be used by the interface code and other codes.

Table 1. The machine code of CNC horizontal lathe

\begin{tabular}{|c|c|c|c|c|c|c|c|}
\hline Code bit & 1 & 2 & 3 & 4 & 5 & 6 & 7 \\
\hline Meaning & $\begin{array}{l}\text { version } \\
\text { number }\end{array}$ & \multicolumn{3}{|c|}{$\begin{array}{l}\text { category code for } \\
\text { machine tools }\end{array}$} & \multicolumn{3}{|c|}{$\begin{array}{l}\text { specification code for } \\
\text { machine tools }\end{array}$} \\
\hline Content & A, B, C, etc. & \multicolumn{3}{|c|}{$\begin{array}{c}\text { VTC: CNC vertical lathe, } \\
\text { STC: specific CNC lathe, } \\
\text { HT: CNC horizontal lathe, } \\
\text { etc. }\end{array}$} & \multicolumn{3}{|c|}{$\begin{array}{l}\text { 403: } 6150, \\
\text { 701: } 6180, \\
\text { 0215: } 2550 \mathrm{hs}, \\
\text { etc. }\end{array}$} \\
\hline Example & A & \multicolumn{3}{|c|}{ HT } & \multicolumn{3}{|c|}{0215} \\
\hline \multicolumn{8}{|c|}{$\begin{array}{l}\text { Note: 1. Considering the large changes of HTC products, the category code of HTC product } \\
\text { is expressed with HT and the specification code of machine tools is expressed with } 4 \text { code } \\
\text { bits. } \\
\text { 2. The specification code of machine tools is mainly used to describe the main } \\
\text { parameters of CNC machine tools. For example, } 2550 \mathrm{hs} \text { means that the maximum cutting } \\
\text { diameter of CNC horizontal lathe is } 250 \mathrm{~mm} \text { and the maximum cutting length is } 500 \mathrm{~mm} \text {. }\end{array}$} \\
\hline
\end{tabular}

The CNC horizontal lathe can be divided into bed module, spindle box module, tailstock module, magazine tool module, bearing module, guide module and transmission module. On this basis, using CNC horizontal lathe as an example and according to the above coding rules, the detailed rule for the module code of CNC horizontal lathe is set up as shown in Table 2. 
Table 2. The module code of CNC horizontal lathe

\begin{tabular}{|c|c|c|c|c|c|c|}
\hline Code bit & 8 & 9 & 10 & 11 & 12 & 13 \\
\hline Meaning & $\begin{array}{c}\text { classification code } \\
\text { for module }\end{array}$ & $\begin{array}{c}\text { characteristic } \\
\text { code for parts }\end{array}$ & $\begin{array}{c}\text { classification code for } \\
\text { parts }\end{array}$ \\
\hline Content & shown in table 3 & $\begin{array}{c}\text { H: weld part, } \\
\text { L: parts, } \\
\text { S: sub-unit }\end{array}$ & $\begin{array}{c}\text { 001: bed, } \\
\text { 002: adjustment plate 1, } \\
\text { 003: adjustment plate 2 }\end{array}$ \\
\hline Example & 01 & L & 001 \\
\hline
\end{tabular}

Table 3. The module classification code of CNC horizontal lathe

\begin{tabular}{|c|c|c|c|c|c|c|c|}
\hline Code & 01 & 02 & 03 & 04 & 05 & 06 & 07 \\
\hline Module & $\begin{array}{c}\text { bed } \\
\text { module }\end{array}$ & $\begin{array}{c}\text { spindle box } \\
\text { module }\end{array}$ & $\begin{array}{c}\text { tailstock } \\
\text { module }\end{array}$ & $\begin{array}{c}\text { magazine tool } \\
\text { module }\end{array}$ & $\begin{array}{c}\text { bearing } \\
\text { module }\end{array}$ & $\begin{array}{c}\text { guide } \\
\text { module }\end{array}$ & $\begin{array}{c}\text { transmission } \\
\text { module }\end{array}$ \\
\hline
\end{tabular}

\subsection{Module interface code}

Module interface code is used to describe the interface information between the modules such as the connection form and the information which the objective module contains, etc. In order to define a set of practical and reasonable module interface code, firstly the module interface should be standardized. Then on the basis of summarizing all information of the module, the interface should be normalized. Only in this way can a practical and reasonable module interface code be made, as well as be convenient for the module configuration process.

In actual modular design process, the number of module interface is uncertain. Each module interface corresponds to a section of module interface code. As the module interface code can only be used in module configuration process, it takes the form of code segments in the object-oriented modular model. The module interface code of CNC machine tools adopts the encoding structure as shown in Figure 2.

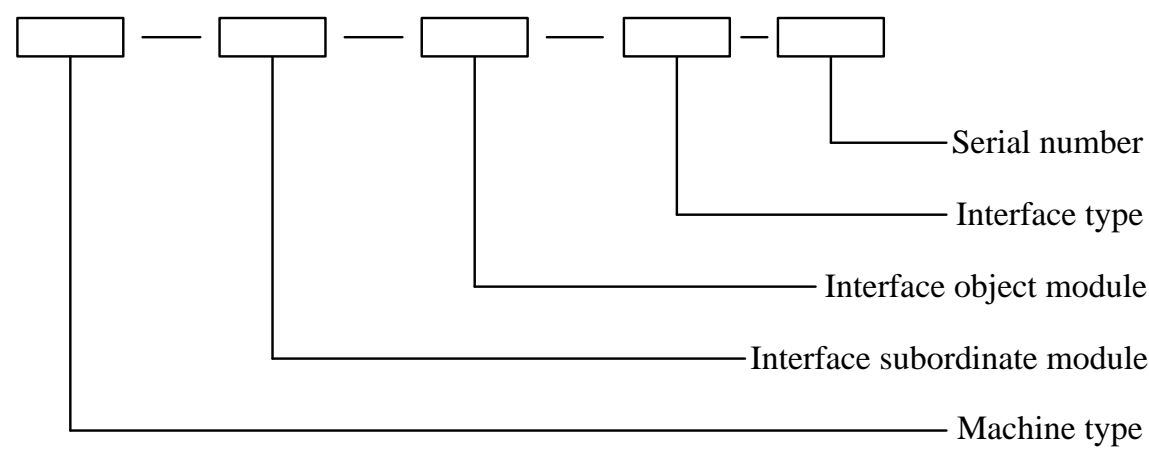

Figure 2. The module interface code of CNC machine tools 
The module interface information includes the interface type, the interface object module, the interface subordinate module, the connection method, the positioning mode, the interface map, and so on. The connection mode and the positioning mode can be reflected on the interface map. The interface map exists in the object-oriented interface data structure as the form of data files, which can be distinguished in the code as the form of the interface serial-number. An interface map uniquely corresponds to a serialnumber, in this way the simplicity can be taken into account.

\subsection{Module drawing code}

In modular design, in order to transform the production control based on the products in the past into the production control based on the modules, the drawings management should be changed accordingly and the drawings should be controlled based on the modules.

At this point, the composition of the module drawing code is changed from "product number + part number + drawing number" into "module main code + drawing code". In addition, the drawing code should indicate not only the serial number of the drawing but also the material of the part and the processing information. In general, the module drawing code should adopt directly the enterprise standard so that it is convenient for the production control. At the same time, it is easier accepted by the industrial engineers. Through the investigation and research of one machine tool enterprise, appropriately considering the actual situation of the machine tool enterprise and on the premise of meeting the needs of the modular design, the rule of module drawing codes suitable for CNC machine tools is developed as shown in figure 3, and specific structure is interpreted as follows.

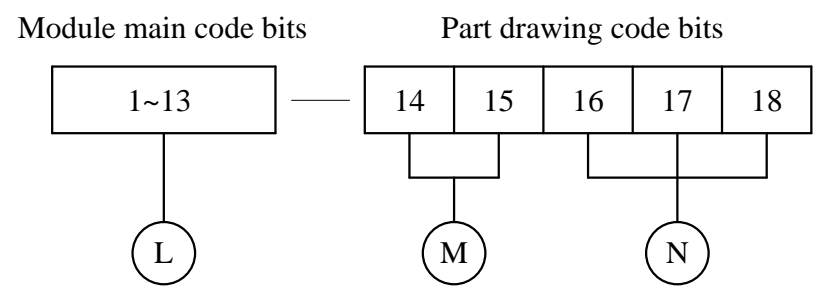

\section{Figure 3. The module drawing code of CNC machine tools}

L: module master code, which obeys the coding rules described above;

M: part material code using two code bits, which describes the material information of the part. Through the analysis on the part material of CNC machine tools from one machine tool enterprise, the part material code is made as shown in table 4. 
Table 4. The part material code

\begin{tabular}{|c|c|c|c|c|c|c|c|}
\hline Code & 00 & 01 & 02 & 03 & 04 & 05 & 06 \\
\hline Meaning & $\begin{array}{c}\text { Assembly } \\
\text { parts }\end{array}$ & 45 & Q235A & 50 Crmo & HT200 & HT250 & HT300 \\
\hline Code & 07 & 08 & 09 & 10 & 11 & 12 & 13 \\
\hline Meaning & TSF & $1 \mathrm{Cr} 13$ & Flexurane & SQSn10-1 & $\begin{array}{c}\text { AISI141 } \\
50 \mathrm{HV}\end{array}$ & $\begin{array}{c}\text { Artificial } \\
\text { marble }\end{array}$ & $\begin{array}{c}\text { Other } \\
\text { materials }\end{array}$ \\
\hline
\end{tabular}

$\mathrm{N}$ : parts drawing serial number with three code bits, which follows the original enterprise standard. In addition, the module master code and the part drawing code are separated by the separation dot. For example, A•HT0215•01L001-1201L is one code case.

\section{The Development of Module Coding System}

\subsection{Data storage and structure of the modules}

The module data storage, according to the form of organization structure, stores the information that the module contains, and the module database is built, which is convenient to control and use the modules.

The module storage structure is used not only to describe the function structure of the module, the management and performance information, the assembly relationship, the interface message, topology and associated information, but also to give an expression to the properties and methods of module operations.

The module storage structure is needed to express the following information.

(1) Supervisory information: It is used to describe the module name, the module class, the internal identification code, the function attribute, the module designer and the string design data, etc.

(2) Structure information: It is devoted to describe the physical dimension of the module, the main structure characteristics and the graphics display.

(3) Technical information: It is used to describe the parts which constitute the module material and the weight etc..

(4) Interface information: It is used to represent the information collection of the module joint elements. The information collection includes the shape of the connection parts, the cooperation between the size and fittings, the assembly feature of the module, and the assembly precision, etc.

(5) Performance information: It is devoted to describe the performance parameters of the module.

(6) Composition information: It is used to describe the sub-module, sub-module name, the functional property and the internal identification code, etc.. 


\subsection{Architecture design of module coding system}

The module coding system developed in this paper is based on JAVA EE development framework, and adopts $\mathrm{B} / \mathrm{S}$ (Browser/Server) mode to achieve the application of enterprise-class coding system with high performance, large capacity, and transaction security. The coding system data and application programs are stored in the server. At the browser end, the user gets the dynamic expansion through downloading the application programs from the server. The server end has multi-layer structure, and the data types processed by B/S system can get dynamic expansion [9]. This structure puts all application logic on the server end and the client end uses web browser to download the applications, which are executed in the browser end.

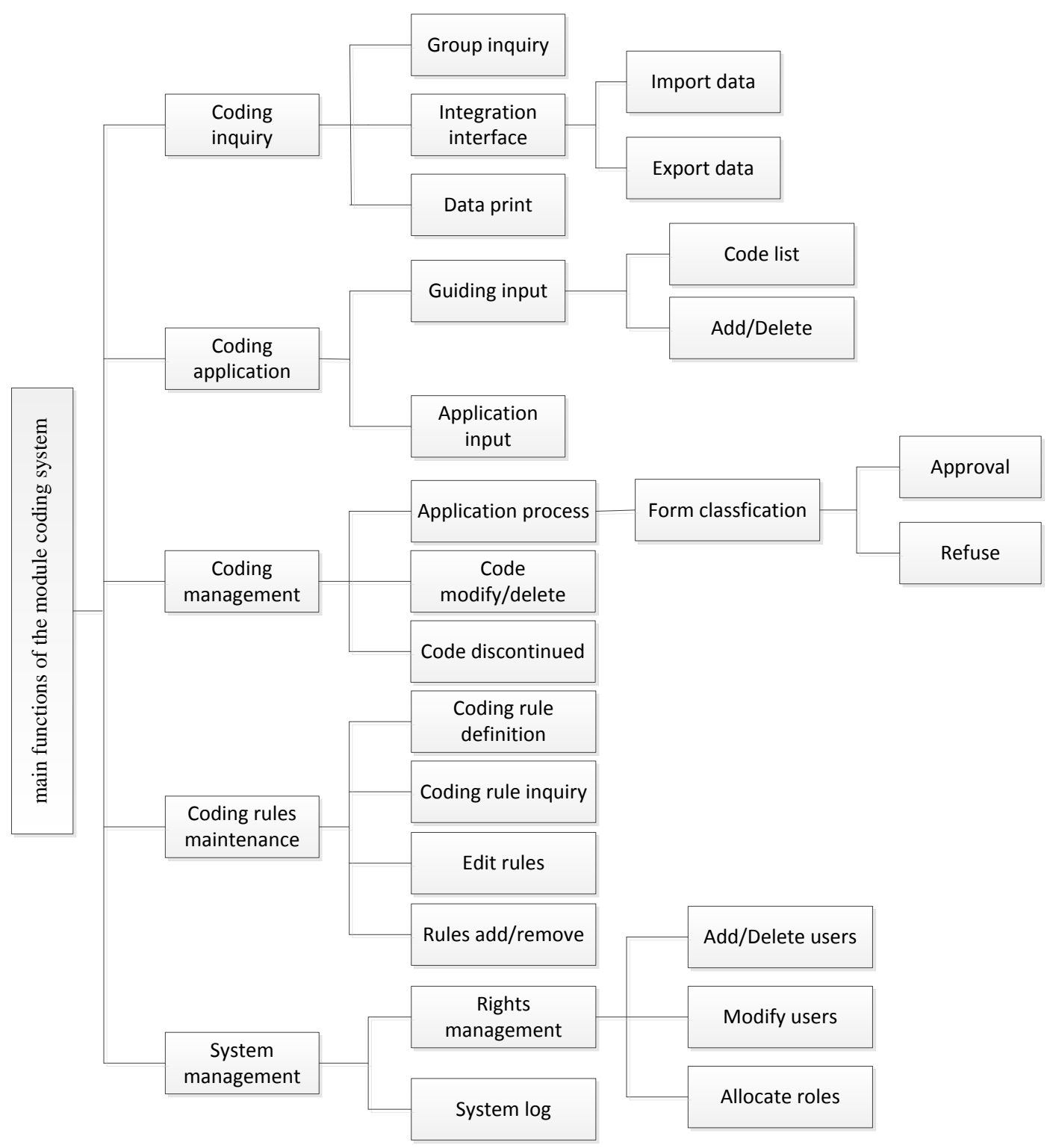

Figure 4. The main functions of the module coding system 


\subsection{Function Design of Module Coding System}

The main functions of the module coding system include: coding inquiry, coding application, coding management, coding maintenance, and system management as shown in Figure 4. The users of the coding system are divided into two types: nonregistered users and registered users. The non-registered users can only query the codes and coding rules, and the registered users have five kinds of access rights including coding application, coding upload, and so on.

\section{1) Coding inquiry function}

The users can easily understand the code with the help of this function including the codes of the parts, the standard parts, the purchased parts and the raw materials.

(1) Group inquiry: It can realize the coding information inquiry with multiple fields (support fuzzy inquiry). There are five keywords the user can inquiry including material type, material name, material model, material specification and material code. When the user can't find what he wants, he can click the "coding application" to get one from the coding system.

(2) Data print: The users can print out the codes what they have queried.

(3) Integration interface: This can help the users export the codes into PDM, ERP, CAD or other application system.

\section{2) Coding application function}

(1) Guiding input: In accordance with the system application, the users make the selection step by step and finally the system automatically generates the code list for the users.

(2) Application process: The user can know the code application process by this function.

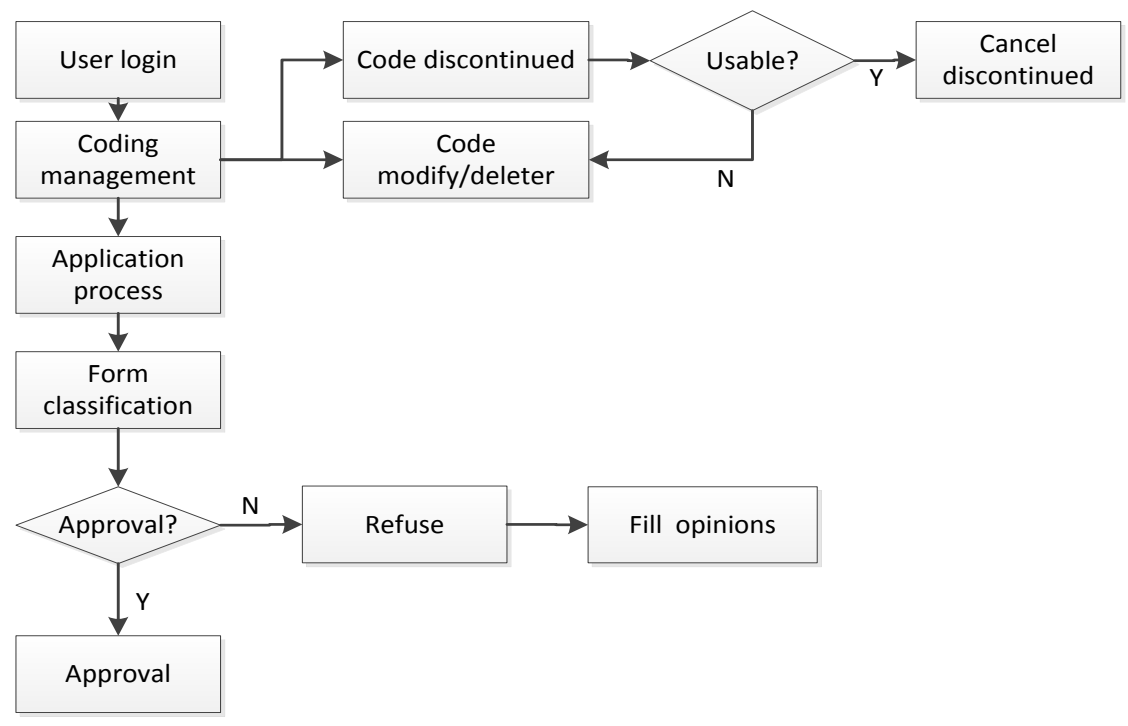

Figure 5. The flowchart of coding management function 


\section{3) Coding management function}

The flowchart of coding management function is shown in Figure 5.

(1) Application process: Firstly, the administrator categorizes the coding application forms according to the application time, the applicants, the time segment of the applications, then carries out the application review. If he agrees with the new code, the administrator clicks "approval", otherwise clicks "refused" and fills the examination and approval opinions. The applicant modifies the application form according to the opinions, which is convenient for the administrator to approval again.

(2) Code modify/delete: The administrator modifies or deletes the code from the code database.

(3) Code discontinued: The administrator discontinues the use of problematic codes. Then select modify, delete after checking or restarting them again.

\section{4) Coding rules maintenance function}

(1) Coding rule definition: The principles are used to encode the modules for machine tools.

(2) Coding rule inquiry: It is used to inquiry the coding rules used in this system.

(3) Edit rules: It is used to modify the coding rules.

(4) Rules add/remove: This is applied to add/ remove the coding rules used in this system.

\section{5) System management function}

(1) Rights management: This function includes two parts: the information management of the users and the information management of the roles, which realizes the basic information maintenance of the users, the role definitions, the authority operation distribution of the roles. The user account of the module coding system is entirely responsible for establishing and issuing by the administrator. The user can modify their account password later.

(2) System log: It is devoted to record the code application tasks.

The operation flowchart of this module coding system is shown in Figure 6. 


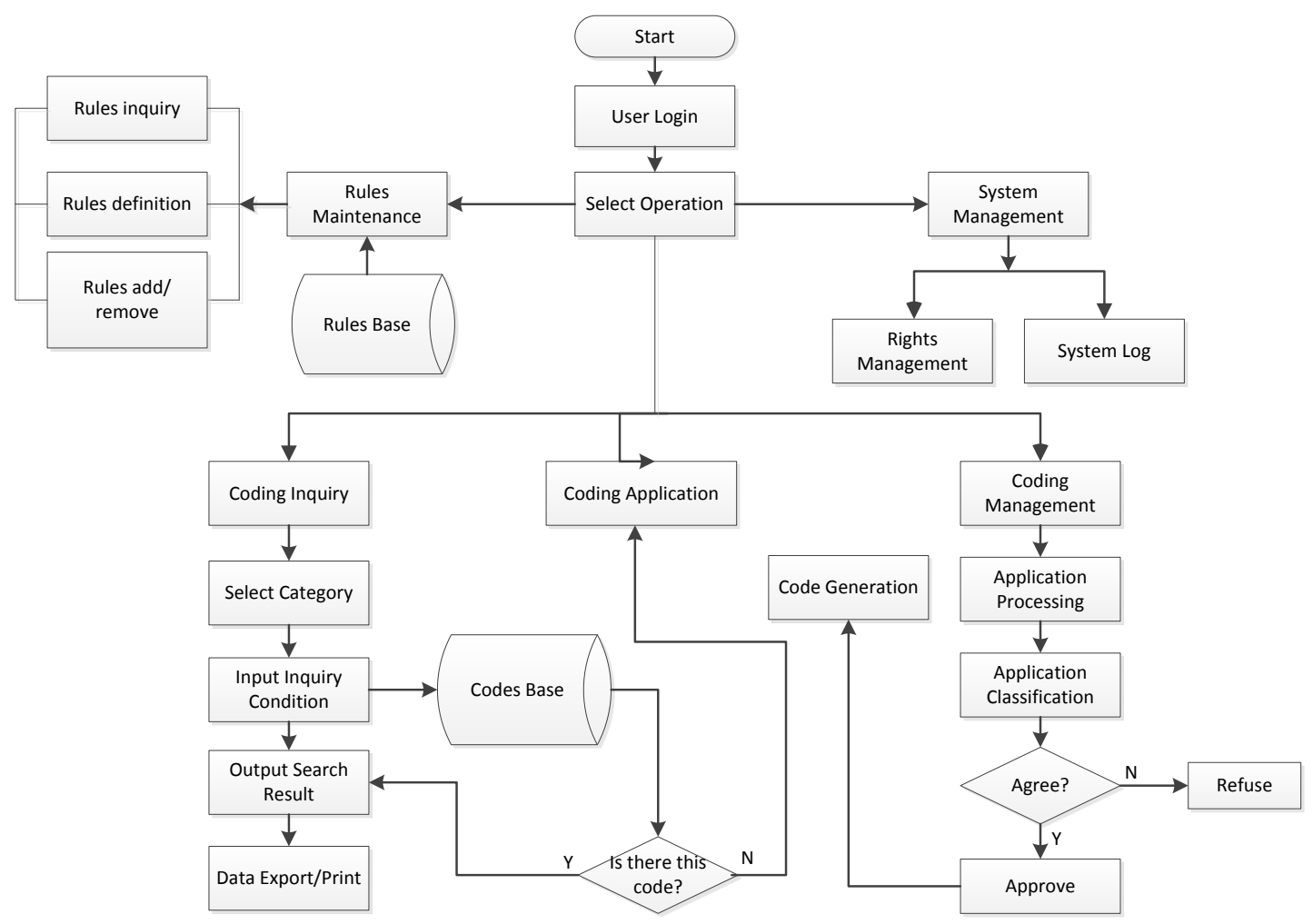

Figure 6. The operation flowchart of the module coding system

\subsection{Software development of the module coding system}

1) Operating system

Considering the stability of the development environment and running speed, Windows XP is chosen as the operating system at the client end in this paper.

2) Development language

The system architecture is based on JAVA EE technology, so this paper uses the object-oriented programming language JAVA to develop the software system, uses JavaScript scripting language as the medium to realize the local computer access, uses the structured database manipulation language Oracle as the relational database language, and uses MyEclipse as the development platform.

3) Testing environment

Java tools SDK JDK 1.6 is used to configure the running environment of Java program. And Apache Tomcat 6. 0 Servlet/JSP is chosen as the server container, which is programmed by Java and not only supports the Servlet and JSP, but also has good characteristics such as convenience, safety. The web browser that supports IE6.0 is used as the client end.

4) Database design

Oracle $11 \mathrm{~g}$ is chosen as the database management system, which can support large capacity. JDBC data source is used as the connection channel for the coding database. The microcomputer is chosen as the hardware environment to ensure the system that 
can be smooth, stable. This paper chooses the mainstream configuration server as the server, and selects the hardware configuration which can support running IE 6.0 browser.

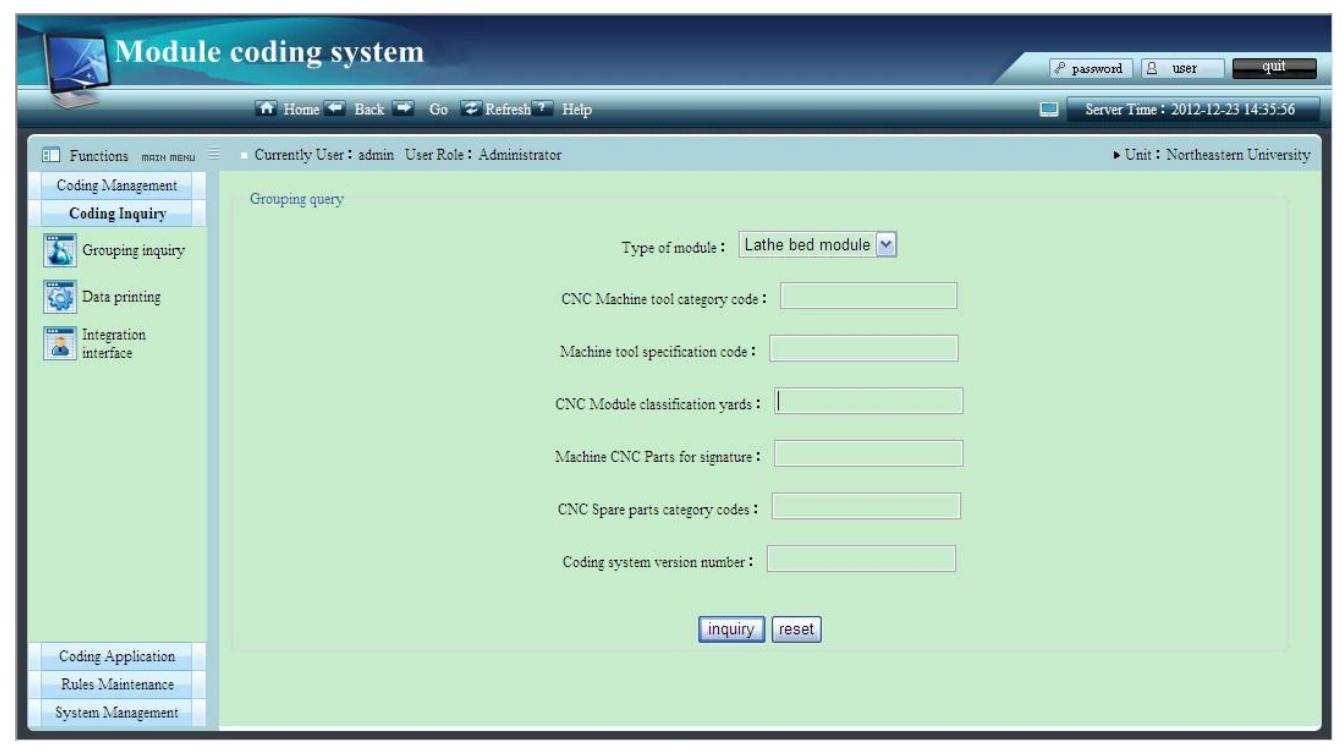

Figure 7. Interface of coding inquiry

\section{5) System implementation}

In order to develop the web database applications, this paper selected DreamWeaver, Servlet and JSP as the development tools. With the help of JSP server-side scripting statements, which is programmed by JAVA, this paper realized the database interaction. As the examples, the interface page of coding inquiry function is shown in figure 7 , and the interface page of coding management function is shown in figure 8 .

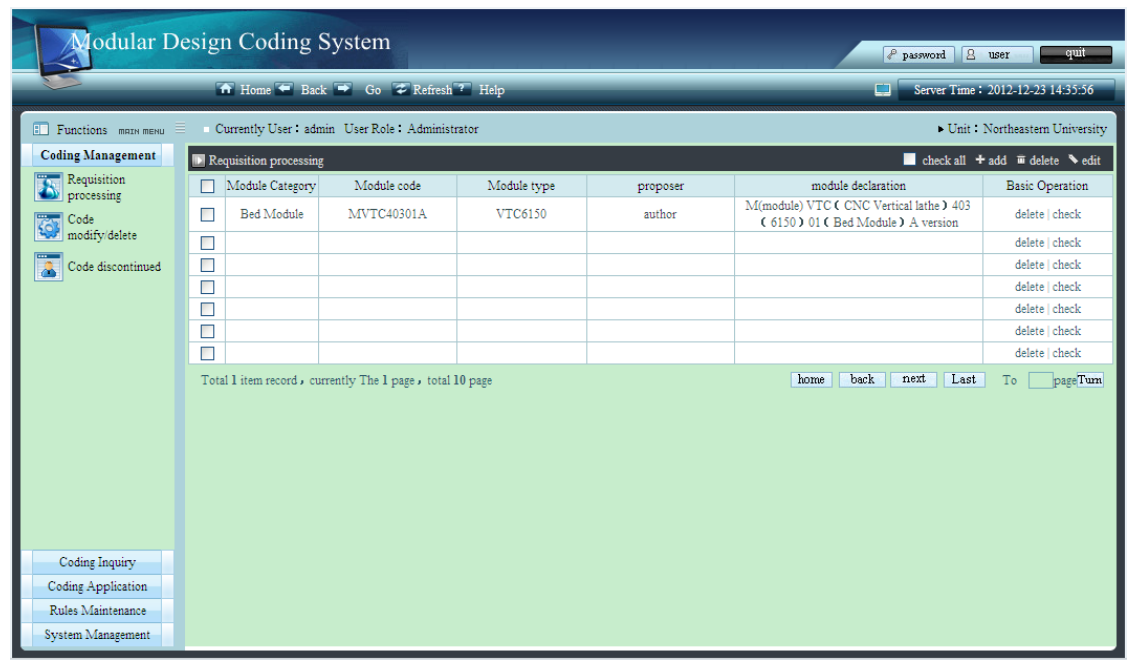

Figure 8. Interface of coding management 


\section{Conclusions}

Module coding is an important step in carrying out the modular design method. In this paper, a module coding system was developed for applying the modular design method for the development of CNC machine tools. This paper analyzed the purposes of the module coding, presented the basic rules of the module coding, determined the coding scheme fit to the requirements of the machine tools enterprise. Based on the $\mathrm{B} / \mathrm{S}$ structure and J2EE platform, this paper completed the function design and software development of the module coding system. The purpose of designing the module coding system is to make the designers easily search and manage the modules in the modular design process for CNC machine tools. The application of this module coding system in one machine tools enterprise proved that it was powerful to promote the development of the enterprise informatization.

\section{Acknowledgements}

This work is supported by the Fundamental Research Funds for the Central Universities (N120403003) and the Research Funds of State "Twelve Five" Support Program (2012BAF10B11).

\section{References}

[1] A. K. Kamrani and S. M. Salhieh, "Product Design for Modularity", Kluwer Academic publishers, Houston, (2002).

[2] L. Zhang, "New Design Methods Application on Microminiature Agricultural Machinery Product Reconfigurable Modular Design”, Science Press, Beijing, (2007).

[3] C. Zhang, "Research on Modular Design Method for CNC Machine Tools", Northeastern University, Shenyang, (2012).

[4] Y. Lou, "A New Method for Machine Tool Modular Coding", Journal of Ningbo University, vol. 11, no. 1, (1998), pp. 67-71.

[5] X. Y. Teng, F. K. Kong and J. T. Zhang, "An approach for module partition of product”, Key Engineering Materials, vol. 419, no. 1, (2010), pp. 257-260.

[6] H. Bai, "Techniques on Constitution of Fly Frames Module and Software System Programming Based on Generalized Modular Design", Tianjin University, Tianjin, (2005).

[7] G. Gao, Y. Xu, H. Lin, B. Chai and W. Wang, "Encoding Method for The Whole Process of The Modular Design and Manufacture", Journal of Tianjin University, vol. 34, no. 2, (2001), pp. 183-187.

[8] P. Gu, M. Hashemian, S. Sosale and E. Rivin, “An Integrated Modular Design Methodology for Life-Cycle Engineering”, CIRP Annals - Manufacturing Technology, vol. 46, no. 1, (1997), pp. 71-74.

[9] J. Liu, "Java web integrated development of return of the king”, Tsinghua University Press, Beijing, (2010).

\section{Authors}

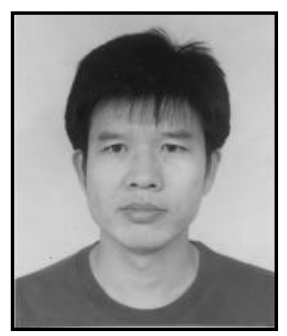

\section{Zhongqi Sheng}

He received his B.Eng. in mechanical design and manufacturing (1994), M.Eng. in mechanics (1997), and $\mathrm{PhD}$ in mechanical manufacturing and automation (2003) from Northeastern University, P.R. China. Since 1997, he is a faculty member in Northeastern University. Now, he is an associate professor in school of mechanical engineering and automation in Northeastern University. His current research interests include modern design theory and methods, computer aided design, mechanical manufacturing and automation. 


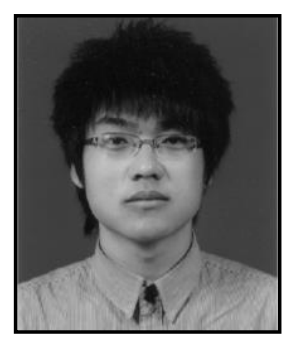

\section{Shujian Zhang}

$\mathrm{He}$ received his B.Eng. in industrial engineering (2012) from Shenyang University of Technology. Currently, he is a graduate student at school of mechanical engineering and automation in Northeastern University, P.R. China. His research interests include mechanical manufacturing and automation, modern design theory and methods.

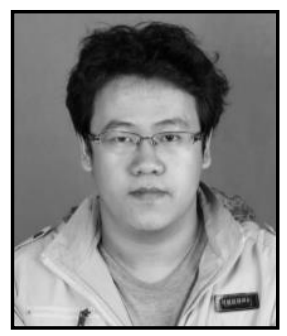

\section{Junyou Song}

$\mathrm{He}$ received his B.Eng. in mechanical design manufacturing and automation (2012) from Qingdao Agricultural University. Currently, he is a graduate student at school of mechanical engineering and automation in Northeastern University, P.R. China. His research interests include mechanical manufacturing and automation, modern design theory and methods. 